\title{
Evolution of insulin resistance in coronary artery disease patients on four different pharmacological therapies
}

\begin{abstract}
Gonzalo Piédrola, Enrique Novo, Joaquín Serrano-Gotarredona, Maria Luisa de Teresa, Rafael García-Robles
\end{abstract}

\begin{abstract}
Summary
The objective of the study was to examine the evolution of insulin sensitivity in a group of patients with stable coronary artery disease receiving one of four different pharmacological therapies. Insulin sensitivity was evaluated using an insulin suppression test in 40 newly diagnosed patients with coronary artery disease and no previous history of metabolic disorders, who were not taking any medication which might affect insulin sensitivity. The insulin suppression test consisted of a constant infusion of glucose, insulin and somatostatin for $150 \mathrm{~min}$; insulin resistance was estimated by determining the steady-state plasma glucose concentrations during the last 60 minutes of the test. The insulin sensitivity index was calculated by the formula: insulin sensitivity index $=($ glucose infusion $\mathrm{rate} / \mathrm{steady}$ state plasma glucose concentrations) $\times 10^{3}$. A second insulin suppression test was performed after 6 months' therapy with either isosorbide mononitrate, atenolol, diltiazem or captopril in 30 of the 40 patients.
\end{abstract}

There were no differences between any of the groups before therapy was initiated. After 6 months, patients treated with captopril and, to a lesser extent, those treated with diltiazem showed statistically significantly decreased steady state plasma glucose concentrations and increased insulin sensitivity index compared to basal values. No statistically significant differences were found in the other two groups. We conclude that captopril and, to a lesser extent, diltiazem improve insulin sensitivity in patients with stable coronary artery disease.

Keywords: insulin resistance; coronary artery disease; captopril; diltiazem

Resistance to insulin-stimulated glucose uptake has been shown to be related to the pathogenesis and development of several metabolic disorders such as hyperinsulinaemia, arterial hypertension, glucose intolerance, obesity, and dyslipidaemia $(\mathrm{box})^{1-2}$; these metabolic abnormalities have been defined as risk factors for coronary artery disease (CAD).
Three prospective studies have shown an independent association between hyperinsulinaemia and CAD in men with no known glucose intolerance. ${ }^{3-5}$ As hyperinsulinaemia can be considered a consequence of insulin resistance when beta cell function is conserved, these studies suggest that hyperinsulinaemia and insulin resistance might be risk factors for CAD. A few recent reports, ${ }^{6}{ }^{7}$ including one of our own, ${ }^{8}$ support this hypothesis, demonstrating that CAD patients are truly insulin resistant, even when confounding risk factors are excluded.

Moreover, the Framinghan Heart Study emphasized the greater morbidity and mortality due to coronary, cerebral and peripheral vascular disease in patients with arterial hypertension. ${ }^{9}$ As a result, courses of treatment were initiated to lower blood pressure in these patients, and consequently, reduce the risk of vascular disease; this was achieved in the case of cerebrovascular disease, however, no significant change was observed in morbidity and mortality resulting from CAD. ${ }^{10}$ This failure has been partly attributed to the possible effects of the drugs used to lower blood pressure on insulin sensitivity. ${ }^{11}$

Since the presence of insulin resistance has been related to the subsequent development of $\mathrm{CAD}$, and the effects of the drugs presently used in the treatment of CAD have yet to be established, the present study attempted to evaluate the effects of four different conventional therapies on the evolution of insulinstimulated glucose uptake, in a group of patients with stable CAD at diagnosis.

Metabolic abnormalities related to underlying decreased insulin sensitivity

- hyperinsulinaemia

- arterial hypertension

- hyperglycaemia and glucose intolerance

- hypertriglyceridaemia

- decreased HDL-cholesterol

- hyperuricaemia

- decreased dehydroepiandrosterone sulfate

- obesity 


\section{Methods}

PATIENTS

Forty newly diagnosed stable angina pectoris patients were included in the study. The diagnosis of CAD was established on the basis of a typical history of exertional chest pain, associated with electrocardiographic (ECG) changes during a treadmill exercise test (ST segment depression $>0.1 \mathrm{mV} ; n=34$ ) and/or significant coronary stenosis on coronary angiography $(n=15)$. None of the patients were taking any medication with potential effects on insulin sensitivity (beta-blockers, diuretics, angiotensin-converting enzyme (ACE) inhibitors, alpha-antagonists), or drugs for coronary heart disease (calcium channel blockers, nitrates), with the exception of acetylsalicylic acid. Patients were excluded if they had a previous history of glucose intolerance or hypertension, body mass index $(\mathrm{BMI})>30 \mathrm{~kg} / \mathrm{m}^{2}$, or fasting plasma glucose $>140 \mathrm{mg} / \mathrm{dl}$. Subjects who had signs or symptoms of cardiac failure, renal failure, liver disease, or other chronic or intercurrent illness were also excluded from the study. The basal characteristics of these patients have been reported previously. ${ }^{8}$

The protocol was approved by the Ramón y Cajal Hospital Ethics Committee, and informed consent was obtained from all patients and controls.

EXPERIMENTAL DESIGN

To determine eligibility, medical history, physical examination (including systolic and diastolic blood pressure measured to the nearest 2 $\mathrm{mmHg}$ using a standard sphyngomanometer by a single, trained examiner), fasting serum biochemical data (glucose, creatinine, liver enzymes, uric acid, lipids and ions), and a 12-lead ECG and treadmill exercise test were performed on the first day.

Insulin sensitivity, as opposed to insulin resistance, was assessed using a modified version of the insulin suppression test (IST). ${ }^{12}{ }^{13}$ This test involved the suppression of endogenous insulin secretion with a sustained infusion of somatostatin. Exogenous crystalline insulin was infused simultaneously, at a constant rate, to achieve a steady state plasma insulin (SSPI). The resultant steady state of plasma glucose (SSPG) in response to a constant glucose infusion was determined.

Patients reported to the EndocrineMetabolic testing room between 08.00 and $09.00 \mathrm{~h}$, after a 12-h overnight fast; two indwelling intravenous lines were placed in both forearm veins and, after 15 to 30 minutes of acclimatisation, basal blood samples were obtained. A continuous infusion of glucose (6 $\mathrm{mg} / \mathrm{kg} / \mathrm{min})$, insulin $(0.77 \mathrm{mIU} / \mathrm{kg} / \mathrm{min})$ and somatostatin ( $125 \mu \mathrm{g}$ in bolus, followed by a constant infusion of $350 \mu \mathrm{g} / \mathrm{h}$ ) was performed for a total of $150 \mathrm{~min}$. Blood samples were obtained at 30, 60, 90, 100, 110, 120, 130, 140, and $150 \mathrm{~min}$, for measurement of plasma glucose and insulin concentrations. The mean of the last seven measurements was used to estimate the SSPI and SSPG achieved during the test. The insulin sensitivity index (ISI) was calculated by the formula:

ISI $(\mathrm{dl} / \mathrm{kg} / \mathrm{min})=($ glucose infusion rate $(\mathrm{mg} / \mathrm{kg} / \mathrm{min})$ $/$ SSPG $(\mathrm{mg} / \mathrm{dl})) \times 10^{3}$

As the insulin and glucose infusion were the same in all subjects (on a $\mathrm{kg}$ basis), the SSPI would be similar in all of them but the resulting SSPG and ISI obtained depended on the individual's disposal of plasma glucose, providing a measure which was directly proportional to the insulin sensitivity, and inversely proportional to the insulin resistance, of the individual patient. The test was performed on each patient before anti-ischaemic therapy was initiated; immediately afterwards, the 40 patients were randomly assigned to one of the following therapeutic groups, with 10 patients per group:

- nitrates: isosorbide mononitrate $(40 \mathrm{mg} / \mathrm{d})$

- calcium antagonists: diltiazem $(180 \mathrm{mg} / \mathrm{d})$

- beta-blockers: atenolol $(50 \mathrm{mg} / \mathrm{d})$

- ACE inhibitors: isosorbide mononitrate (40 $\mathrm{mg} / \mathrm{d})+$ captopril $(25 \mathrm{mg} / \mathrm{d})$

All patients also received $200 \mathrm{mg}$ acetylsalicylic acid (ASA) daily.

After 6 months of anti-ischaemic therapy, patients were asked to return to the EndocrineMetabolic testing room, where a second IST was performed.

ASSAYS

Plasma glucose was assayed by the glucose oxidase method (Beckman Glucose Analyzer, Beckman Instruments, Fullerton, CA, USA). A commercial radioimmunoassay was used for determination of serum insulin (Sorin Biomedica SpA, Saluggia, Italy). C-Peptide levels were measured by another commercial radioimmunoassay (Incstar Corporation, Stillwater, MN, USA). The mean intra- and interassay coefficients of variation, as reported by the manufacturer, were $7.6 \%$ and $8.9 \%$ for insulin and $6.2 \%$ and $14.8 \%$ for C-peptide, respectively.

STATISTICAL ANALYSIS

When studying the differences in SSPG, SSPI and ISI between groups prior to treatment, a one-way analysis of variance was performed. In SSPG, natural logarithm transformation was carried out because variances were unequal. The analysis of a nested design was used to study the differences between levels before and after therapy in each group, applying the Bonferroni correction for multiple comparisons when interaction was significant; three factors were present:

- therapy, with four levels (nitrates, calcium antagonists, beta-blockers, angiotensin converting enzyme inhibitors), a fixed effect factor

- SSPG, ISI and SSPI evolution, with two levels (basal and after therapy), a fixed effect factor

- persons, a random-effect factor nested in groups.

A difference of $\mathrm{p}<0.05$ was considered significant. The results are expressed as mean $\pm S D$ in tables, and as mean $\pm S E$ in figures. 
Table Steady-state plasma glucose (SSPG), steady-state plasma insulin (SSPI), insulin sensitivity index (ISI), fasting plasma glucose (FPG), fasting plasma insulin (FPI), fasting plasma C peptide (FPCP), age and BMI attained during the first insulin suppression test (performed prior to therapy) in patients with newly diagnosed CAD, according to the four different groups studied: nitrates $(n=7)$, calcium antagonists $(n=8)$, beta-blockers $(n=7)$, ACE inhibitors $(n=8)$. Data are expressed as mean \pm SD. There were no statistically significant differences in any of the parameters

\begin{tabular}{lllll}
\hline & Nitrates & Ca antagonists & $\beta$-Blockers & ACE inhibitors \\
\hline SSPG $(\mathrm{mg} / \mathrm{dl})$ & $206.65 \pm 62.39$ & $220.82 \pm 77.17$ & $235.75 \pm 43.43$ & $240.05 \pm 28.66$ \\
SSPI $(\mathrm{mU} / \mathrm{ml})$ & $52.64 \pm 11.20$ & $59.23 \pm 10.34$ & $53.44 \pm 10.78$ & $56.12 \pm 16.93$ \\
ISI $(\mathrm{dl} / \mathrm{kg} / \mathrm{min})$ & $32.29 \pm 13.01$ & $30.97 \pm 12.88$ & $26.30 \pm 5.49$ & $25.33 \pm 3.22$ \\
FPG $(\mathrm{mg} / \mathrm{dl})$ & $96.57 \pm 17.22$ & $95.50 \pm 3.96$ & $95.85 \pm 13.29$ & $103.00 \pm 14.84$ \\
FPI $(\mathrm{mU} / \mathrm{ml})$ & $11.71 \pm 2.44$ & $14.45 \pm 11.58$ & $14.34 \pm 7.28$ & $12.30 \pm 4.76$ \\
FPCP $(\mathrm{ng} / \mathrm{ml})$ & $1.95 \pm 1.02$ & $2.87 \pm 3.08$ & $2.17 \pm 1.66$ & $1.34 \pm 0.91$ \\
Age $(\mathrm{years})$ & $65.00 \pm 8.60$ & $60.25 \pm 10.22$ & $62.71 \pm 7.45$ & $60.87 \pm 11.70$ \\
BMI $\left(\mathrm{kg} / \mathrm{m}^{2}\right)$ & $24.71 \pm 1.21$ & $26.24 \pm 3.03$ & $26.59 \pm 2.87$ & $26.28 \pm 2.51$ \\
\hline
\end{tabular}

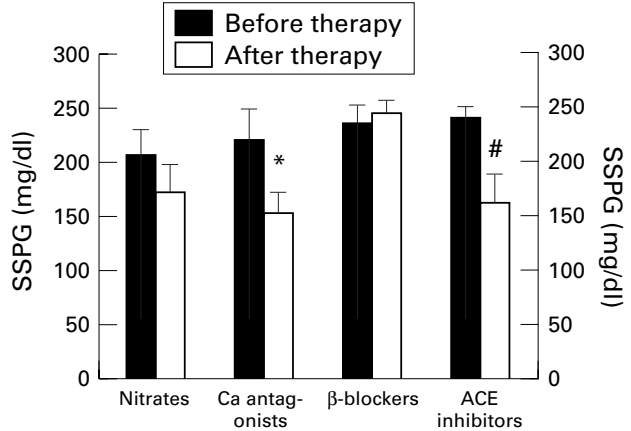

Figure 1 Steady state plasma glucose (SSPG) levels after 6 months therapy in patients with newly diagnosed CAD. The columns represent the mean \pm SE. ${ }^{\star} \mathrm{p}<0.001$ and $\# \mathrm{p}<0.0005$ vs before therapy

\section{Results}

Thirty of the 40 patients were re-evaluated after 6 months of treatment (eight in the calcium antagonists and ACE inhibitors groups and seven in the nitrates and betablockers groups). The remaining 10 no longer fulfilled the study requirement and were therefore excluded (three required more drugs during the follow-up period, three did not give a reason, two required by-pass surgery due to their CAD, one went abroad and one died). Thus, the following data only refer to the 30 patients who were re-evaluated

There were no differences in the values obtained during the first IST (performed before therapy was initiated) in SSPG, ISI, SSPI, fasting plasma glucose, fasting plasma insulin, fasting plasma $\mathrm{C}$ peptide, age or BMI between the four groups studied (table).

The results of the second IST showed that SSPG values had decreased significantly during the 6-month follow-up period in patients treated with ACE inhibitors or with calcium antagonists (figure 1), whilst no differences were observed in the other groups (nitrates and beta-blockers). Similarly, ISI levels were significantly higher after treatment in the patients who received ACE inhibitors and, to a lesser extent, calcium antagonists, but no differences were observed in the other two groups (figure 2).

The SSPIs obtained during both ISTs were similar in all groups. No differences were found in fasting plasma glucose, fasting plasma insu-

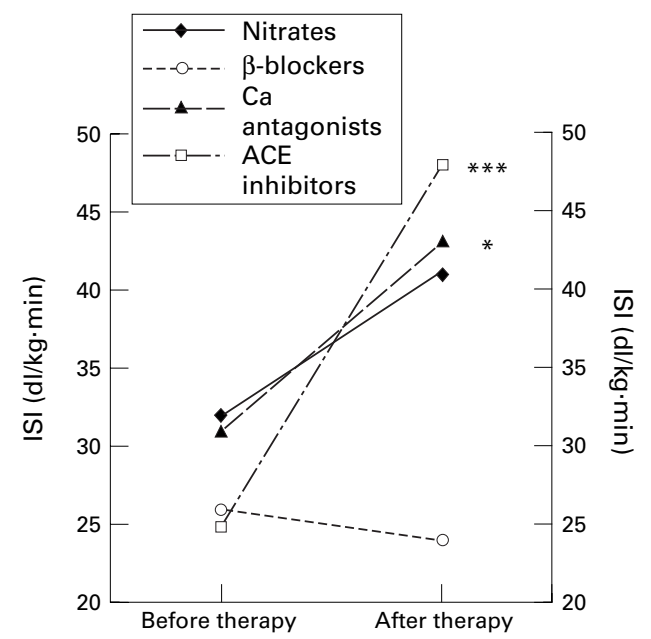

Figure 2 Evolution of insulin sensitivity index (ISI) levels after 6 months therapy in patients with newly diagnosed CAD. Values are means $\pm \mathrm{SE}$ of the groups. ${ }^{\star} \mathrm{p}<0.05$ and ${ }^{\star \star \star} \mathrm{p}<0.001$ vs before therapy

lin or fasting plasma C-peptide before and after therapy between any of the groups. There was no significant change in BMI during the study.

\section{Discussion}

Resistance to insulin-stimulated glucose uptake and hyperinsulinaemia have been related to the pathogenesis and development of several metabolic abnormalities, including noninsulin-dependent diabetes mellitus (NIDDM), hypertension, dyslipidaemia and obesity, ${ }^{12}$ which are well known risk factors for CAD. Following Reaven's definition of the metabolic syndrome $\mathrm{X},{ }^{1}$ numerous studies have attempted to clarify this complex web of disorders and their relationship with the subsequent development of atherosclerosis and, particularly, CAD. Patients with both microvascular angina ${ }^{14}$ and organic coronary stenosis ${ }^{7}$ have been shown to be insulin resistant, even when the characteristic risk factors are excluded. ${ }^{8}$

Since these patients are insulin resistant, the effects of standard CAD treatments on insulin sensitivity may be an important factor, as any beneficial or harmful actions may influence the accompanying coronary morbidity and mortality. ${ }^{15}$ The metabolic effects of these drugs have been investigated extensively in arterial hypertension, ${ }^{11}$ but have yet to be 
studied in $\mathrm{CAD}$; in general, $\mathrm{ACE}$ inhibitors have been reported to improve insulinstimulated glucose uptake, both in NIDDM $^{16}$ and in non-diabetic hypertensive patients, ${ }^{17}$ and to decrease fasting plasma glucose and glycated haemoglobin in diabetic hypertensive patients. ${ }^{18}$ However, the role of calcium antagonists in glucose metabolism has not been completely elucidated; reports range from alterations in insulin liberation in non-diabetic patients treated with nifedipine ${ }^{19}$ to both neutral ${ }^{20}$ and beneficial results found with diltiazem, with amelioration of hyperinsulinaemic resistance. ${ }^{21}$ Beta-blockers, both non-selective and beta-1 selective adrenergic antagonists, have been shown to worsen glucose tolerance ${ }^{22}$ and to decrease insulin sensitivity ${ }^{23}$ in hypertensive patients; these deleterious metabolic consequences seem to be related not only to a peripheral decrease in glucose oxidation ${ }^{24}$ but also to inhibition of insulin release by beta cells. ${ }^{25}$ No clear metabolic effects of nitrates have been reported to date. ${ }^{26}$

Stress is known to increase insulin resistance. ${ }^{27}$ Our patients were very probably under some stress during the first IST; the stress would probably have been much lower in the second IST as the test was no longer new to them; this would not alter the beneficial results found with captopril and diltiazem, since the statistical method evaluates the differences in evolution of the four groups studied and not the individual variation with respect to pretreatment values. However, it does emphasize the deterioration in SSPG and ISI throughout the evolution of the atenolol group (in contrast to the other three groups).

The technique used to quantify insulin sensitivity was the insulin suppression test, a simple and cost-effective alternative to the euglycaemic hyperinsulinaemic clamp (considered the gold standard method) for the measurement of insulin resistance, which has been used increasingly often in recent years. ${ }^{713} 28$ The IST consists of a constant intravenous infusion of glucose and insulin, with the addition of epinephrine and propranolol to suppress endogenous insulin secretion, although this is actu-

1 Reaven GM. Banting lecture. Role of insulin resistance in human disease. Diabetes 1988;37:1595-607.

2 DeFronzo RA, Ferrannini E. Insulin resistance: a multifaceted syndrome responsible for NIDDM, obesity, hypertension, dyslipidemia and atherosclerotic cardiovascular disease. Diabetes Care 1991;14:173-94.

3 Fontbonne AM, Charles MA, Thibult N, et al. Hyperinsulinemia as a predictor of coronary heart disease mortality in a healthy population: the Paris Prospective Study. 15-year in a healthy population: the Paris Prospecti

4 Wellborn TA, Wearne K. Coronary heart disease incidence and cardiovascular mortality in Busselton with reference to glucose and insulin concentrations. Diabetes Care 1979;2: $154-60$

5 Pyörälä K. Relationship of glucose tolerance and plasma insulin to the incidence of coronary heart disease: results of two population studies in Finland. Diabetes Care 1979;2: 131-41.

6 Inchiostro S, Bertoli G, Zanette G, Donadon V. Evidence of higher insulin resistance in NIDDM patients with ischaemic heart disease. Diabetologia 1994;37:597-603.

7 Shinozaki K, Suzuki M, Ikebuchi M, et al. Insulin resistance associated with compensatory hyperinsulinemia as an independent risk factor for vasospastic angina. Circulation 1995; 92:1749-57.

8 Piedrola G, Novo E, Serrano-Gotarredona J, et al. Insulin resistance in patients with a recent diagnosis of coronary artery disease. 7 Hypertens 1996;14:1477-82. ally achieved by somatostatin infusion. We have been using this method successfully in both dogs and humans, ${ }^{829}$ without major problems.

Our study shows the effects of four conventional courses of treatment for CAD on insulin sensitivity. Captopril produced a highly significant improvement in insulin sensitivity $(p=0.0008)$. Some improvement was also seen on diltiazem $(p=0.0340)$. Insulin sensitivity did not appear to worsen notably with the use of atenolol, although it should be borne in mind that only seven patients could be re-evaluated, and that this was the only group in which there was an apparent tendency towards worsening. Isosorbide mononitrate did not seem to have any effect on insulin sensitivity. These data seem to corroborate the reported effects of these drugs on insulin sensitivity in hypertensive patients, and support a possible beneficial role for captopril, and possibly diltiazem, in the treatment and secondary prevention of CAD.

For the reasons mentioned above, and since captopril and diltiazem seem to offer beneficial metabolic profiles in the long-term treatment of CAD, it would appear advisable to administer the first two drugs in preference to atenolol, at least in cases where there is no clear cardiological indication for the beta-blocker. However, it must be remembered that many factors, other than metabolic ones, intervene in the pathogenesis of CAD; therefore, these recommendations should be followed with great caution.

In conclusion, we have demonstrated that the use of captopril and, to a lesser extent, diltiazem by CAD patients is accompanied by an improvement in insulin sensitivity. Therefore, captopril and diltiazem might be regarded as a first choice therapy in the management of $\mathrm{CAD}$, especially in the presence of associated metabolic anomalies.

This research was supported by Clinical Investigation Grant from the Hospital Ramón y Cajal, Madrid, Spain (GP) and Research Proyect Grant \# 93/1 (BMS) from Plan Nacional de Fomento a la Investigación, Spain

We are indebted to Mrs María Teresa Embid, Mrs Purificación Moyano and Mrs Anne J Macmichael for their technical assistance.

9 Kannel WB, Ward GW. A decade of advances in preventive cardiology. Prim Cardiol 1985;9:19-34.

10 MacMahon SW, Cutler JA, Furberg CD, Payne GH. The effects of drug treatment on morbidity and mortality from cardiovascular disease: a review of randomized controlled trials. Prog Cardiovasc Dis 1986;29:99-118.

11 Black HR. The coronary artery disease paradox: the role of hyperinsulinemia and insulin resistance and implications for therapy. 7 Cardiovasc Pharmacol 1990;15(suppl 5):S26-S38.

12 Harano Y, Ohgaku S, Hidaka H, et al. Glucose, insulin and somatostatin infusion for the determination of insulin sensitivity. $\mathcal{F}$ Clin Endocrinol Metab 1977;45:1124-7.

13 Shen DC, Shieh SM, Fuh M, Wu DA, Chen YDI, Reaven GM. Resistance to insulin stimulated glucose uptake in GM. Resistance to insulin stimulated glucose uptake in patients with $1988 ; 66: 580-3$.

14 Botker HE, Moller N, Ovesen P, et al. Insulin resistance in microvascular angina. Lancet 1993;342:136-40.

5 Reaven GM. Treatment of hypertension: focus on prevention of coronary heart disease. f Clin Endocrinol Metab 1993;76:537-40

16 Torlone E, Rambotti AM, Perriello G, et al. ACE-inhibition increases hepatic and extrahepatic sensitivity to insulin in patients with type 2 (non-insulin-dependent) diabetes mellitus and arterial hypertension. Diabetologia 1991;34:119-25.

17 Pollare T, Lithell H, Berne C. A comparison of the effects of hydroclothiazide and captopril on glucose and lipid metabolism in patients with hypertension. $N$ Engl $\mathcal{F}$ Med
1989;321:868-73. 
18 Prince MJ, Stuart CA, Padia M, Bandi Z, Holland OB. Metabolic effects of hydrochlorothiazide and enalapril during treatment of the hypertensive diabetic patients: enalapril for
hypertensive diabetics. Arch Intern Med 1988;148:2363-8.

19 Charles S, Ketelsleger JM, Buysschaert M, Lambert AE. Charles S, Ketelsleger JM, Buysschaert M, Lambert AE.
Hyperglycaemic effect of nifedipine. BMF 1981;289:19-20.

20 Pollare T, Lithell H, Mörlin C, Prantare H, Hvarfner A Ljunghall S. Metabolic effects of diltiazem and atenolol: results from a randomized, double blind study with parallel groups. F Hypertens 1989;7:551-9.

21 Beer NA, Jakubowicz DJ, Beer RM, Nestler JE. Disparate effects of insulin reduction with diltiazem on serum dehydroepiandrosterone-sulfate levels in obese hypertensive men and women. 7 Clin Endocrinol Metab 1994;79:1077-81.

22 Stein PP, Black HR. Drug treatment of hypertension in patients with diabetes mellitus. Diabetes Care 1991;14:42548 .

23 Pollare T, Lithell H, Selinus I, Berne C. Sensitivity to insulin during treatment with atenolol and metoprolol: a randomised, double blind study of effects on carbohydrate and lipoprotein metabolism in hypertensive patients. $B M \mathcal{F}$ and lipoprotein mi298:1152-7.
24 DeFronzo RA, Thorin D, Felber JP, et al. Effect of beta and alpha adrenergic blockade on glucose-induced thermogenesis in man. $\mathcal{F}$ Clin Invest 1984;73:633-9.

25 Cerasi E, Luft R, Efendie S. Effect of adrenergic blocking agents on insulin response to glucose infusion in man. Acta Endocrinol 1972;69:335-46.

26 Oreklov AN, Boldenkov GN, Tutou VV, et al. Cardiovascular drugs and atherosclerosis: effects of calcium antagonists, beta-blockers and nitrates on atherosclerotic characteristics on human aortic cells. $\mathcal{f}$ Cardiovasc Pharmacol 1988;12(suppl 6P):S66-S68.

27 Mizock BA. Alterations in carbohydrate metabolism during stress: a review of the literature. Am $\mathcal{F}$ Med 1995;98: $75-84$.

28 Maheux P, Jeppesen J, Sheu WHH, Hollenbeck CB, Clinkingbeard C, Greenfield MS. Additive effects of obesity, hypertension, and type 2 diabetes on insulin resistance. Hypertension 1994;24:695-8.

29 Martínez FJ, Villa E, Serrano J, García-Robles R. Diagnosis of insulin resistance. Drugs 1993;46(suppl 2):165-71.

\section{Medical Anniversary \\ John Singer Sargent, 12 January 1856}

John Singer Sargent (1856-1925) was an artist, not a doctor, but he will always be remembered for painting (1905) the Big Four founding professors of the new Johns Hopkins University, namely

- William Osler, Professor of Medicine

- William Welch, Professor of Pathology

- William Halsted, Professor of Surgery

- Howard Kelly, Professor of Obstetrics.

Sargent was born in Florence where his parents happened to be spending the winter. His father was a Philadelphia ophthalmologist. Young Sargent, an American migrant to Europe, was taught to paint in Paris, and eventually acquired his own studio in Tite Street, Chelsea, London, where he composed the Big Four painting, which now hangs in the Welch Library of the Johns Hopkins Hospital. Sargent grouped the four professors around a huge Venetian globe. On the wall is seen an El Greco entitled 'St Martin of Tours dividing his cloak with the beggar'. Welch's arm rests on an original volume of Petrach, which is now housed in the Johns Hopkins library.

Sargent became the most celebrated portrait painter of his day. He was elected to the Royal Academy (1894) and received numerous honours. In 1907 Edward VII recommended him for a knighthood but this was not conferred because he was an American. He died a bachelor in 1925 and is buried at Brookwood Cemetery, Surrey. - DG Fames 